\title{
Origin Mechanism of Tightness of Chang 6 Sandstone Reservoir in Zhiluo Oilfield, Ordos Basin
}

\author{
Zhang Rongjun \\ College of Petroleum Engineering \\ $\mathrm{X}$ i'an Petroleum University \\ Xi'an, China \\ e-mail:rjzhang@xsyu.edu.cn. \\ GENG Qian \\ College of Petroleum Engineering \\ $\mathrm{X}$ i'an Petroleum University \\ Xi'an, China \\ e-mail:277270933@qq.com
}

\author{
ZHANG Qian \\ State Key Laboratory of Continental Dynamics \\ Northwest University \\ Xi'an, China
}

\begin{abstract}
By the use of basic geological data, properties, cash thin section, SEM, particle size, high mercury injection and other core analysis experiments are completed to make a detail study on the Chang 6 group characteristics of Zhiluo oil field in diagenesis perspective. The results reveals that sandstone's petrography types are mainly gary or dark gray fine grain arkosic, the pore of which mainly consists of primary remanent intergranular pore and secondary induced pore. The mainly types of pore structure are subtle throat-coarser skewness and subtle throat-finer skewness. The type of reservoir is extra-low porosity and ultra-low permeability lithologic reservoir. Porosity have bad correlation with permeability. The density of lithologic reservoir is controlled by both deposition and diagenesis, and the later is the internal cause of the improvement of reservoir's property. Compaction and cemention reduces primary porosity $19.2 \%$ and $13.61 \%$, respectively. Secondary induced pore due to dissolution increases porosity about $3.64 \%$ and make the property of reservoir better. The study provides a reliable basis for similar reservoir further exploration and development.
\end{abstract}

Keywords-Zhiluo oilfield; Chang 6 reservoir; property; diagenesis; reservoir

\section{INTRODUCTION}

Chang 6 sandstone reservoir in Zhiluo oilfield of Yan'an region is one of the important oil /gas exploration and development interval in Yanchang Oilfield, located in the south of northern Shaanxi slope, Ordos Basin(Fig .1). Predecessors have been done related geological studies work about Chang 6 sandstone reservoir in Zhiluo Oilfield $^{[1-6]}$. They think that the structure of Chang 6 reservoir is western-leaning monoclinal, and the inner layer structure with low amplitude nose-like uplift; Depositional environments are shallow lake of delta front deposition; Provenance mainly controlled by the northeast; Diagenesis is one of the factors affecting the reservoir tightness; Reservoir types are mainly tight lithologic reservoir with low porosity and ultra-low permeability; The main controlling factors of reservoir properties are sedimentary microfacies. However, because of the knowledge about characteristics of the Chang 6 sandstone reservoir in Zhiluo Oilfield are insufficient currently, especially microscopic characteristics, diagenesis characteristics, evaluation of the relative high-quality reservoir and other aspects, the exploration and development progress in Chang 6 reservoir has been further restricted. In this paper, based on basic geological data, by the use of cash thin section, SEM, properties, Xrays and other tests with qualitative and quantitative methods, a detail analysis has been made, which about reservoir microscopic space, properties, diagenesis and other characteristics from the microscopic view, and provides basis for Chang 6 reservoir further exploration and development.

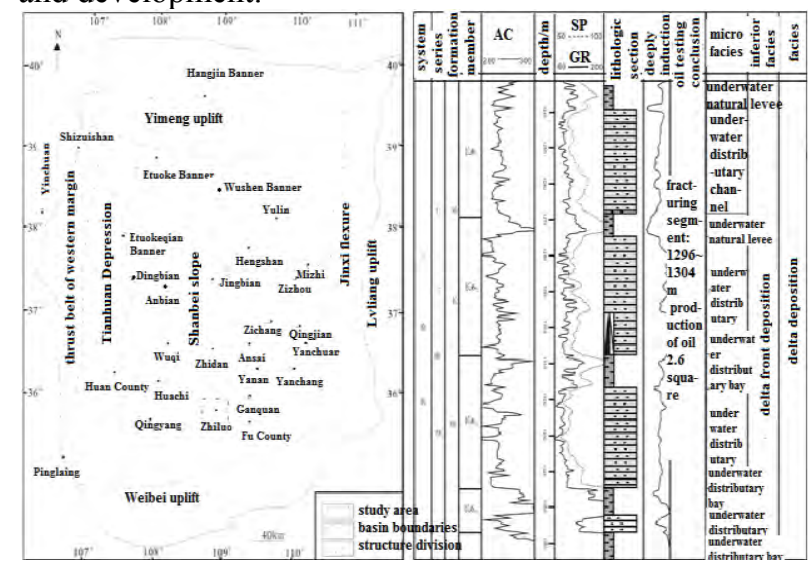

Figure 1. Tectonic location and synthetical stratum histogram of the Chang 6 reservoir in Zhiluo Oilfield 


\section{PROPERTIES CHARACTERISTICS OF RESERVOIR}

For tight lithologic reservoir, properties are one of the crucial factors to the quality of the reservoir, and the size and distribution of porosity and permeability are visualized parameters to indicate deposition-diagenesis construction and reservoir reformation ${ }^{[7,8]}$. Trough Statistics and analysis to 367 pieces cores in Chang 6 layer(Fig .2), porosity of samples ranges from $3.76 \%$ to $14.66 \%$, average porosity is $8.89 \%$, ultra-low porosity reservoir is $2.18 \%$, extra-low porosity reservoir $80.64 \%$, low porosity reservoir $17.18 \%$, it reveals that the samples are mainly extra-low porosity reservoir; permeability of samples ranges from $0.042 \times 10^{-3} \mu \mathrm{m}^{2}$ to $6.25 \times 10^{-3} \mu \mathrm{m}^{2}$, average permeability is $0.637 \times 10^{-3} \mathrm{~mm}^{2}$, extra-low permeability reservoir is $9.81 \%$, ultra-low permeability reservoir $90.19 \%$, low permeability reservoir $17.18 \%$, it reveals that the samples are mainly ultra-low permeability reservoir. According to comprehensive statistics and analysis, the samples are mainly extra-low porosity and ultra-low permeability reservoir ${ }^{[12]}$, it reveals that the Chang 6 layer in research area is tight sandstone lithologic reservoir, and deposition and diagenesis mainly as a destroyer in reservoir construction and reformation.

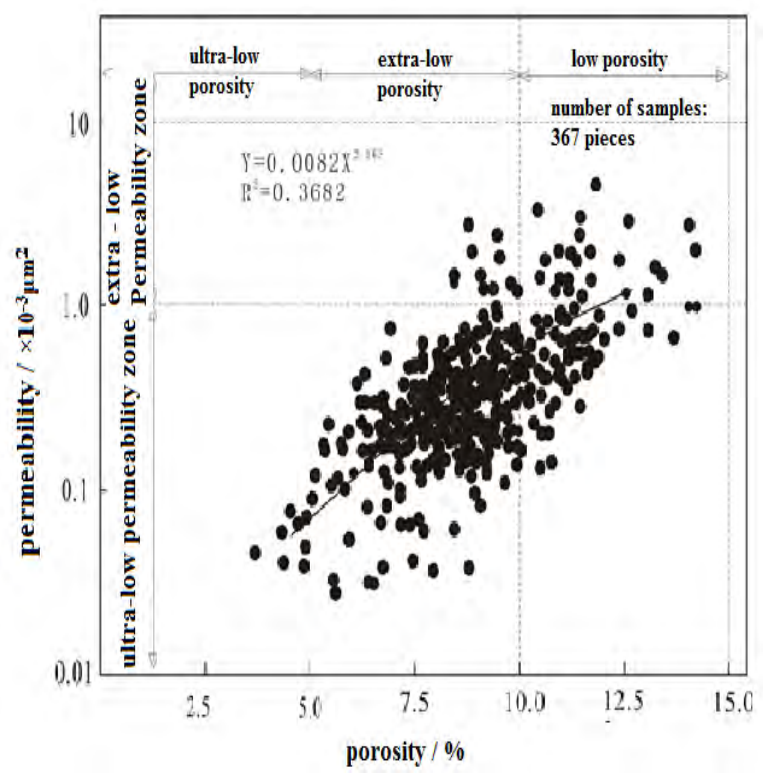

Figure 2. Relationship of porosity and permeability of Chang 6 reservoir in Zhiluo Oilfield

\section{ORIGIN MECHANISM OF TIGHTNESS OF THE RESERVOIR}

\section{A. lithological characteristics of reservoir}

According to core observation of 12 cored wells on Chang 6 reservoir in Zhiluo Oilfield and cast thin section's identification, statistics, analysis of 106 core samples , 106 cast thin core samples, Chang 6 reservoir's petrography types are mainly gray or dark gray fine grain feldspathic sandstone, followed by a small amount of silty fine sandstone, siltstone feldspathic sandstone, and lithic feldspathic sandstone are less (Fig .3). It reveals that provenance of Chang 6 reservoir is single and stable.
Quartz content in the clastic components are mainly about $15.6 \% \sim 30.1 \%$; Feldspar content mainly for $20.3 \% \sim 57.9 \%$, with plagioclase and potassium feldspar based; The cuttings content are about $64.4 \% \sim 10.2 \%$, mainly composed of metamorphic rocks (quartzite, schist, slate, phyllite), igneous (eruption rocks and aphanite) and a small amount of sedimentary rocks; Black mica content mainly for $1.0 \sim 7.4 \%$. Compositional maturity is low, and index $(\mathrm{Q} /(\mathrm{F}+\mathrm{R})$ primarily for the value of 0.15 to 0.6 . The overall content of the interstitial material is mainly about $7.5 \% \sim 17.8 \%$, with authigenic mineral based, argillaceous matrix content is low, cements are mainly chlorite, illite, calcite, laumontite.

The sandstone with a high degree of detrital weathering, particle separation is middle-well, grinding roundness is mostly subangular, structural maturity is medium, and the average particle size is mainly $0.15 \sim 0.30 \mathrm{~mm}$, indicating the low-energy depositional environment of the stability of the provenance. Contact patterns between detrital are mainly line contact, a small amount are curve shaped contact. The main types of cementation are pore, film and film-pore cementation, a small amount are increase and compression embedded pore cementation.

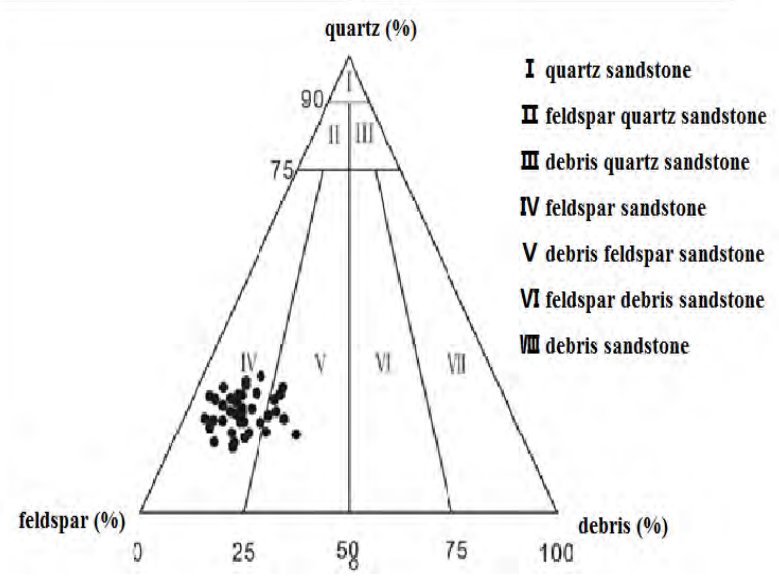

Figure 3. Clastic rock detrital composition triangle plot of Chang 6 reservoir in Zhiluo Oilfield

\section{B. The impact of reservoir micro-pore structure on reservoir properties}

\section{1) Characteristics of reservoir space}

Based on identification, statistics and analysis about reservoir sandstone cast thin, SEM data, pore evolution characteristics and pore formation mechanism of Chang 6 reservoir in the process of sedimentation, diagenesis. The main reservoir space are remaining intergranular pores and secondary dissolved pores after compaction and cementation. Primary intergranular pores edges between particles are mostly wrapped with chlorite or illite clay mantle, some primary pore edges are corrosion, the facial porosity ratio content of intergranular pore is mainly $0.4 \% \sim 6.5 \%$, pore radius is mainly $15 \mu \mathrm{m} \sim 70 \mu \mathrm{m}$, the relative content of intergranular pore is about $75 \%$ to the total facial porosity ratio(Fig .4). Secondary dissolved pores are mainly feldspar dissolved pores, debris dissolved pores and laumontite dissolved pores, facial porosity ratio are mainly $0.1 \% \sim 3.2 \%, \quad 0.0 \% \sim 2.3 \%, \quad 0.0 \% \sim 4.6 \%$, respectively. Dissolved pore radius vary greatly, mainly 
about $5.0 \mu \mathrm{m} \sim 90 \mu \mathrm{m}$, a part of the pore radius up to $110 \mu \mathrm{m}$ or more. The relative content of dissolved pores is about $20 \%$ to the total facial porosity ratio(Fig .4). To build a good bridge for enhance the ability to improve reservoir seepage, dissolution develops a large number of secondary tiny throats. Secondly, crystal intergranular pores are produced in the process of diagenetic mineral cementation, the content is low, the relative content of crystal intergranular pores is about $1.0 \%$ to the total facial porosity ratio(Fig .4), mainly by laumontite crystal intergranular pores, illite crystal intergranular pores, chlorite crystal intergranular pores, etc.;However, microcracks generated in the diagenesis process are rare, and they are mainly mechanical compaction particles broken fracture and dissolved cleavage aperture.

2) Characteristics of micro-pore structure

It is a microscopic rock physical property that microscopic pore structure characteristics to indicate reservoir quality of the reservoir rock directly, and development characteristics of microscopic pore structure reflects the extent of construction and renovation to the reservoir by deposition, diagenesis and tetonism, then the fluid's seepage law can be controlled by microscopic spatial characteristics of the reservoir ${ }^{[7-11]}$.

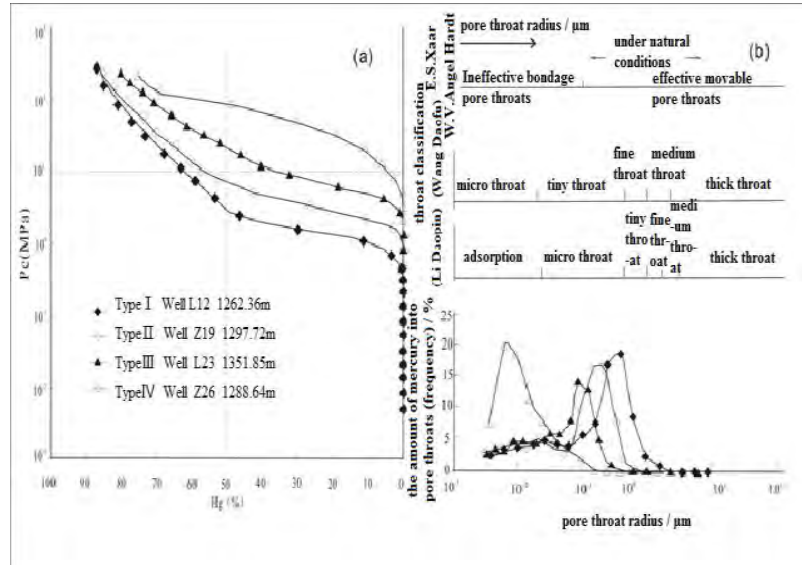

Figure 4. Capillary pressure curve of mercury porosimetry of Chang 6 reservoir in Zhiluo Oilfield

On the basis of high pressure mercury injection, physical properties, cast thin sections test and analysis, the study samples can be divided into four types pore structures after comparison and analysis(Table 1, Fig .4): Type I is fine-subtle throat-coarse skewness, type II is subtle throat-coarser skewness type, type III is subtle throat-finer skewness, type IV is subtle throat-fine skewness. From the analysis of Table 1 and Fig .3, reservoir is given priority to tight diagenesis in the process of diagenetic transformation, and the average porosity of the samples is $8.65 \%$, with an average permeability of $0.57 \times 10^{-3} \mu^{2}$; Heterogeneity of reservoir microscopic pores and throats is strong, pore throat radius distribution range is relatively large, the main pore throat radius range from $0.025 \mu \mathrm{m}$ to $3.0 \mu \mathrm{m}$, with about 120 times difference; Pores combination by intergranular pores-dissolved pores to micropores; Threshold pressure is little higher than medium, with the sample average of $3.64 \mathrm{MPa}$; The main flow channels are submicron throats, which radius are smaller than $1.0 \mu \mathrm{m}$. From this analysis, the mainly types of micro-pore structure are type II and type III in Chang 6 reservoir in research zone, and seepage pore throat radius are mainly $0.05 \mu \mathrm{m} \sim 1.0 \mu \mathrm{m}$, dissolution porosity is developed.

\section{The impact of diagenesis on reservoir physical properties}

Sandstone reservoir characteristics and distribution of Yanchang formation in Ordos Basin are influenced by sedimentary facies, diagenesis and other multiple factors. Effects of diagenesis on reservoir properties include compaction, cementation and dissolution ${ }^{[5-6,7-8,13]}$.

According to comprehensive statistics and analysis of rock thin section, cast thin section, SEM data, etc., Chang 6 reservoir in research zone experienced strong diagenesis, and diagenetic stage mainly in the middle-diagenetic phase $\mathrm{A}^{[5-6,14]}$. Influenced by strong compaction and cementation, rocks in Chang 6 reservoir become more tight, reducing rock porosity, permeability and physical properties greatly; On the other hand, chlorite film has a protective effect on reservoir porosity ${ }^{[5,8]}$, and secondary dissolved pores can increase reservoir facial porosity ratio and improve reservoir porosity and permeability parameters.

1) The impact of pressolution and compaction on reservoir properties

Mechanical compaction of Chang 6 reservoir mainly occurs in the early diagenesis, and its role result: the particles occur compaction orientation, so that the long axes of detrital grains are nearly horizontal orientation, and it is common that rocks grain levels have aligned mica and charcoal under the microscope and on the core; To compact the soft particles deform, mainly to make igneous rock debris, mica, argillaceous debris and others bend or stretch by compression or embedded with hard clastics; Contact relationship among detrital grains change. With burial depth increases, the contact relationships among particles gradually close, and debris particles from isolated with each other to close, so linear contact characteristics emerge(Fig .5-a). Compaction causing loss to Chang 6 reservoir porosity about $19.2 \%$, which indicates that compaction is the main controlling factor of tight reservoir properties.

\section{2) The impact of cementation on reservoir properties}

\section{a) Cementation of carbonate}

Based on statistics and analysis of sandstone cast thin and SEM microscopy data, cementation of calcite, iron calcite, dolomite and other carbonate minerals have appeared(Fig .5-a, b). Among them, the iron calcite, ankerite relatively more, but the total amount of cements is low. Calcite are mostly fine-grained cements, and it also form contiguous embedded crystal cementations in part layers, (Fig .5-a); Dolomite often present as diamond euhedral crystal. Various types of carbonate cements dispersed and filled in the pores have some impact on reservoir porosity and permeability, and the result is porosity becomes smaller or make reservoir become tight as a non-reservoir. While it plays a part in support that the early carbonate cements fill in the pores, reducing compaction degree of sandstones. Meanwhile, iron calcite fill in feldspar or debris secondary pores, so that cementation of carbonate is one of the main reasons for reducing porosity and permeability of the reservoir, which can last after dissolution and damage the reservoir greatly. 
TABLE I. THE STATISTICAL PARAMETERS OF MICRO- PORE STRUCTURE CHARACTERISTICT

\begin{tabular}{|c|c|c|c|c|c|c|c|c|c|}
\hline \multirow[t]{2}{*}{$\begin{array}{c}\text { Ty } \\
\text { pe } \\
\text { s }\end{array}$} & Porosity & $\begin{array}{l}\text { Permeabil- } \\
\text { ity }\end{array}$ & $\begin{array}{l}\text { Threshold } \\
\text { pressure }\end{array}$ & $\begin{array}{c}\text { The } \\
\text { maximum } \\
\text { of mercury } \\
\text { intake } \\
\text { saturation }\end{array}$ & $\begin{array}{l}\text { Pore throat } \\
\text { radius of } \\
\text { mainstream } \\
\text { seepage }\end{array}$ & $\begin{array}{c}\text { Sorting } \\
\text { coefficient }\end{array}$ & \multirow[t]{2}{*}{$\begin{array}{c}\text { The } \\
\text { skewness } \\
\text { of the } \\
\text { pores and } \\
\text { throats }\end{array}$} & \multirow[t]{2}{*}{$\begin{array}{c}\text { The main } \\
\text { pores } \\
\text { combinati- } \\
\text { on }\end{array}$} & \multirow{2}{*}{$\begin{array}{c}\text { Nu } \\
\text { m- } \\
\text { ber } \\
\text { of } \\
\text { sam } \\
- \\
\text { ples }\end{array}$} \\
\hline & $/ \%$ & $/ 10^{-3} \mu \mathrm{m}^{2}$ & /Mpa & $/ \%$ & $/ \mu \mathrm{m}$ & & & & \\
\hline \multirow[t]{2}{*}{ I } & $9.0 \sim 14.0$ & $0.70 \sim 6.0$ & $0.25 \sim 1.0$ & $80.0 \sim 92.0$ & $0.1 \sim 3.0$ & $2.0 \sim 3.0$ & \multirow[t]{2}{*}{$0.11 \sim 0.27$} & \multirow{2}{*}{$\begin{array}{c}\text { Intergranular } \\
\text { pores- } \\
\text { dissolved } \\
\text { pores }\end{array}$} & \multirow[t]{2}{*}{8} \\
\hline & $(10.85)$ & $(1.24)$ & $(0.56)$ & $84.60)$ & $(0.42)$ & $(2.62)$ & & & \\
\hline \multirow[t]{2}{*}{ II } & $7.0 \sim 13.0$ & $0.3 \sim 3.0$ & $0.6 \sim 2.5$ & $75.0 \sim 85.0$ & $0.07 \sim 0.8$ & $1.5 \sim 3.0$ & \multirow[t]{2}{*}{$-0.16 \sim 0.15$} & \multirow[b]{2}{*}{$\begin{array}{c}\text { Intergranular } \\
\text { pores- } \\
\text { dissolved } \\
\text { pores; } \\
\text { Dissolved } \\
\text { pores- } \\
\text { intergranular } \\
\text { pores }\end{array}$} & \multirow[t]{2}{*}{13} \\
\hline & (9.67) & $(0.62)$ & (1.42) & $(80.24)$ & $(0.15)$ & $(2.21)$ & & & \\
\hline \multirow[t]{2}{*}{ III } & $6.0 \sim 10.0$ & $0.1 \sim 1.0$ & $1.0 \sim 4.0$ & $65.0 \sim 85.0$ & $0.05 \sim 0.5$ & $1.5 \sim 2.5$ & \multirow[t]{2}{*}{$-0.42 \sim 0.08$} & \multirow{2}{*}{$\begin{array}{c}\text { Micropores- } \\
\text { dissolved } \\
\text { pores }\end{array}$} & \multirow[t]{2}{*}{17} \\
\hline & $(8.26)$ & $(0.37$ & $(2.17)$ & $(74.62)$ & $(0.096)$ & $(1.96)$ & & & \\
\hline \multirow[t]{2}{*}{ IV } & $<7.0$ & $<0.3$ & $>2.5$ & $<80$ & $<0.2$ & $<2.5$ & \multirow[t]{2}{*}{$-0.62 \sim-0.1$} & \multirow[t]{2}{*}{ Micropores } & \multirow[t]{2}{*}{6} \\
\hline & $(6.14)$ & $(0.09)$ & $(4.66)$ & $(70.18)$ & $(0.03)$ & $(1.47)$ & & & \\
\hline
\end{tabular}

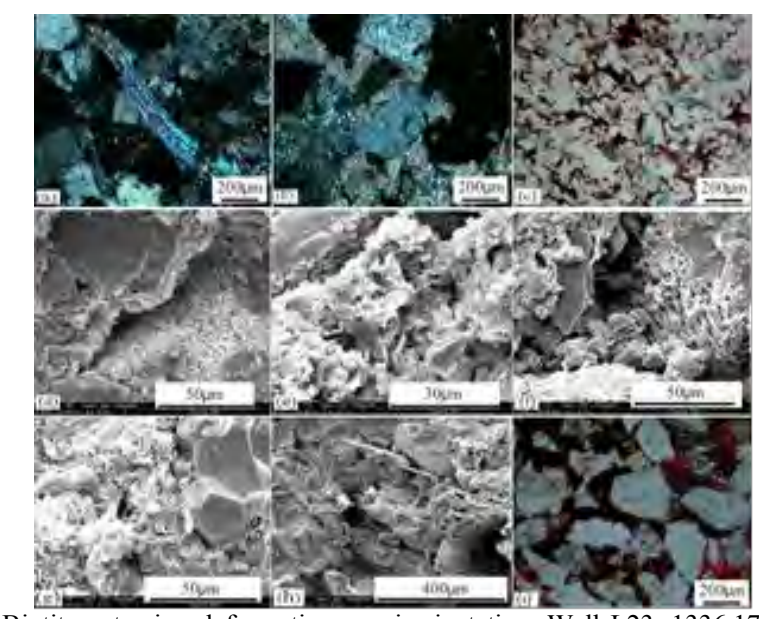

a.Biotite extrusion deformation, semi-orientation, Well L23, $1336.17 \mathrm{~m}$ cast $(+)$; b.Crystalline calcite filling in intergranular pores and dissolved pore, Well Z13, $1298.71 \mathrm{~m}$, cast $(+)$; c.Ankerite filling dissolved pores, Well Z26, 1286.93m, cast ( - ) ; d.Chlorite film on the surface of particles, Well L14, 1306.24m, SEM; e.Flaky illite filling pores, Well Z18, 1249.82m, SEM; f.Laumontite dissolution, siliceous increase, illite cementation, Well Z27, 1274.56m; g.Siliceous increase, chlorite cementation,Well Z18, 1252.16m, SEM; h.Feldspar dissolution, chlorite film cementation, Well Z19, 1298.27m, SEM; i.Feldspar and rock dissolution, feldspar dissolution seams, clay mineral adsorption of organic materals, Well L12, $1264.95 \mathrm{~m}$, SEM.

Figure 5. Photos of cast section and SEM in Chang 6 reservoir

\section{b) Authigenic clay minerals and laumontite} cementation

The main clay cements in research area are chlorite, illite, illite/montmorillonite mixed-layers and other minerals(Fig .5-d, e). Chlorite mostly output in the form of pores liner(Fig .5-d); Illite and illite/montmorillonite mixed-layers minerals mainly output in the form of porefilling(Fig .5-e). Argillaceous cement are mainly chlorite cementation, which are very common throughout the research area. Clay films occupy certain spaces, and their presence also allows primary intergranular pores smaller obviously. When clay minerals forming, they often occupy the pore throats, making throats thinning, or even disappear, thereby reducing permeability of the sandstone reservoir.

Under the microscope, laumontite cementation minerals mainly exist in the form of pore-filling(fig- $f$ ), distributing as cluster, about $2.62 \%$, and can be dissolved easily(Fig .5-f). Its feldspathic dissolution provides better material basis for the formation of laumontite.

\section{c) Siliceous cementation}

Under the microscope, siliceous cement relatively more developed in Chang 6 sandstone reservoir, and mainly manifested as authigenic increased edges of quartz and authigenic quartz in the study area(Fig .5-f, g). There are two types of siliceous cementation observed in the microscope: the first is secondary overgrowth quartz, which often forms crystal surface of euhedral quartz ,commonly seen in thin quartz overgrowth phenomenon, and the degree of increasing varies; The second is pore-filling cementation, secondary quartz at the late stage forms after compaction. The euhedral degree of quartz with pore filling is high, generally products as single crystal, also presents set along the pore edges(Fig .5-f, g). Quartz overgrowth have adverse effects on the formation of secondary porosity, which is an important cause of poor properties of the sandstone reservoir in study area. But on the other hand, due to the high rigidity of silica, a small number of overgrowth increase contact points among skeletal particles at the early stage, increasing compaction capacity of the reservoir, thus contributing to save the intergranular pores. Siliceous content in study area is little, generally less than $1 \%$, so it has little effect on the reservoir. 
Through identification, statistics, and comparative analysis of cast thin data and SEM pictures, combined with physical properties data, the correlation between cement content and physical properties in Chang 6 is generally low, mainly weak negative correlation. cementation reduces porosity about $13.61 \%$ totally at the early and late stage, which destructive effects weaker than compaction. It is showed that the destruction of cementation acts on reservoir properties second only to compaction.

3) The impact of dissolution on reservoir properties

The main dissolution minerals of Chang 6 reservoir are feldspar, debris and laumontite in study area(Fig .5-f, h, i). It is common that feldspar dissolution usually occur under conditions of acidic porous water medium, which rich in $\mathrm{CO}_{2}$ and organic acids ${ }_{-}^{[6]}$. Feldspar, laumontite and debris are dissolved along their cleavage joints, micro cracks and grain boundaries(Fig .5-f, h, i). The formation of dissolved pores play a constructive role that improve developments of pores and throats and connectivity among them. Part of the carbonate cements, accountable substances are dissolved, thereby the conditions of porosity and permeability are improved. Secondary pores are produced by dissolution, which improve the permeability and reservoir properties for Chang 6 reservoir in study area, and dissolution offers secondary porosity and average porosity for reservoir spaces about $1.5 \% \sim 5.6 \%$ and $3.64 \%$, respectively. It is suggested that dissolution is a major contributor to the transformation of reservoir properties.

\section{CONCLUSION}

1.Clastic components of Chang 6 reservoir in study area are mainly fine grain or silty fine feldspathic sandstone, and the provenance is single and stable; Structural maturity and compositional maturity of minerals is medium and low, and cements are mainly chlorite, illite, calcite, laumontite, with low argillaceous matrix content.

2.Reservoir space in study area is combination of middle-small pores, mainly by intergranular pores (facial porosity ratio: $0.4 \% \sim 6.5 \%$ ), secondary pores are mainly feldspar dissolved pores, debris dissolved pores, laumontite dissolved pores, and crystal intergranular pores, and facial porosity ratios are $0.1 \% \sim 3.2 \%, 0.0 \% \sim 2.3 \%$, $0.0 \% \sim 4.6 \%$, respectively. Microcracks generated in the diagenesis process are rare, and the physical properties of reservoir are mainly extra-low porosity and ultra-low permeability.

3.The density of lithologic reservoir is mainly controlled by both deposition and diagenesis, and the former is the basis of the construction of reservoir space's, which decides the quality of reservoir; the evolution process of the later is complex, highlighting the multiplicity. Compaction and cementation reduces primary porosity $19.2 \%$ and $13.61 \%$, respectively. Secondary induced pore due to dissolution increases porosity about $3.64 \%$ and make the property of reservoir better.

\section{REFERENCES}

[1] [1]Cheng Wen, Wang Chengyu, Qiu Annan. Sedimentary microfacies characteristics and new understandings of Chang $6_{3}$ sand layer groups, the upper Triassic, Huan County area, Ordos Basin [J]. Journal of Palaeogeography, 2012, 14(6).

[2] [2]Wang Qizong, Li Wenhou, Zhao Hong, etc. Lake facies turbidite characteristics and significance of Yanchang Formation, the Triassic, southeastern section of Ordos Basin [J]. Geological Sciences, 2006, 41(1): 54-63.

[3] [3]Xie Zhengwen, Xie Yuan, Wang Jian, etc. Sequence stratigraphy's control of reservoir in Fu County area, Yanchang Formation [J]. Mineralogy and Petrology, 2004, 24(2): 95-103.

[4] [4]Wei Bin, Wei Honghong, Chen Quanhong, etc. Provenance analysis of the Yanchang Formation, the Upper Triassic, Ordos Basin [J]. Northwest University (Natural Science), 2003, 4.

[5] [5]Wang Caiping. Study on diagenesis and porosity evolution of Chang 6 Reservoir in Zhiluo Oilfield, Ordos Basin [J]. Earth Sciences and Environment, 2010, 32(2): 161-165.

[6] [6]Bai Ru, Zhang Jingong, Li Wei, etc. Diagenesis and favorable diagenetic facies of Chang 6 reservoir in Yanchang Formation, the Upper Triassic, Zhiluo Oilfield, Fu County area [J]. Geological Bulletin, 2013, 32(5): 790-798.

[7] [7]Ren Dazhong. Fine descriptions of low-ultra low permeability lithologic reservoir [D]. Northwest University, 2012.

[8] [8]Wei Hu, Ren Dazhong, Gao Fei, etc. Microscopic pore structure characteristics and the impact on the physical properties of low permeability sandstone reservoir - following Chang 2 reservoir in Liu Luo Yu, Xiasiwan Oilfield as an example [J]. Petroleum Geology and Engineering, 2013, 27(2): 26-29.

[9] [9]Ren Dazhong, Sun Wei, Wei Hu, etc. Diagenetic facies types and microscopic pore structure characteristics of Chang 8 reservoir in Huaqing Oilfield [J]. Geoscience, 2014, 28(2): 79-87.

[10] [10] M.Scherer. Parameters Influencing Porosity in Sandstones : A Model for Sandstone Porosity Prediction[J]. AAPG Bulletin, 1987, $71: 485-491$.

[11] [11]Sun Wei, Shi Chengen, Zhao Jingzhe, etc. X-CT scanning imaging technology used in microscopic pores structure and seepage mechanism of ultra-low permeability reservoir - following Chang $8_{2}$ reservoir in Zhuang 19 formation, Xifeng Oilfield [J]. Geological Journal, 2006, 80(5): 775-779.

[12] [12]The National Energy Administration (NEA) .SY/T 6285-2011, Reservoir evaluation method [S]. Beijing: Petroleum Industry Press, 2011.

[13] [13] Alaa M, Salem S, Morad S, et al. Diagenesis and reservoir quality evolution of fluvial sandstones during progressive burial and uplife : evidence from the Upper Jurassic Boipeba Member , Reconcavo basin, Northeastern Brazil[J].AAPG Bulletin, 2000, 84(7) : 1015-1040.

[14] [14]State Economic and Trade Commission.SY/T 5477-2013, Stages of clastic diagenesis [S]. Beijing: Petroleum Industry Press, 2013 . 